\title{
Climate change impacts: accounting for the human response
}

\author{
Michael Oppenheimer
}

Received: 18 July 2011 / Accepted: 1 August 2012 / Published online: 29 August 2012

(C) The Author(s) 2012. This article is published with open access at Springerlink.com

\begin{abstract}
The assessment of potential impacts of climate change is progressing from taxonomies and enumeration of the magnitude of potential direct effects on individuals, societies, species, and ecosystems according to a limited number of metrics toward a more integrated approach that also encompasses the vast range of human response to experience and risk. Recent advances are both conceptual and methodological, and include analysis of some consequences of climate change that were heretofore intractable. In this article, I review a selection of these developments and represent them through a handful of illustrative cases. A key characteristic of the emerging areas of interest is a focus on understanding how human responses to direct impacts of climate change may cause important indirect and sometimes distant impacts. This realization underscores the need to develop integrated approaches for assessing and modeling impacts in an evolving socioeconomic and policy context.
\end{abstract}

\section{Introduction}

Systematic assessment of potential impacts of climate change began over 30 years ago (see for example, Williams 1978) but the problem is complex so progress has been quite gradual. Among other difficulties, impacts don't occur "to" human and natural systems as if the latter were inert, but occur "with" these systems in the sense that both human and natural systems are responsive. In the case of humans, response occurs not only to actual physical impacts, but to the expectation of those impacts. All this has been known since the inception on impact studies, but estimating and modeling or even qualitatively assessing such responses requires not only an improved ability to identify such interactions but additional techniques for their quantification. Impacts arise across a vast spectrum of physical stimuli, socioeconomic contexts, governance structures, and psychological and cultural predispositions of those affected. For some impacts, making headway may require a new conceptual

This article is part of a Special Issue on "Improving the Assessment and Valuation of Climatic Change Impacts for Policy and Regulatory Analysis” edited by Alex L. Marten, Kate C. Shouse, and Robert E. Kopp.

M. Oppenheimer $(\bowtie)$

Program in Science, Technology, and Environmental Policy, Woodrow Wilson School and Department of Geosciences, Princeton University, Princeton, NJ 08544, USA

e-mail: omichael@princeton.edu 
framework altogether. The challenge was set out long ago, among others by Kates (1985) who diagrammed the complexity of the problem and referred to an objective of "comprehensive impact assessment" which even today remains a remote ideal for integrated assessment.

Fortunately, the climate impacts arena has been intellectually open and flexible, accommodating a very diverse array of approaches. Accordingly, substantial progress can occur not only via the sometimes painfully slow process of generation of new ideas, but perhaps more quickly by developing new combinations of existing methodologies, some borrowed from neighboring or even unrelated disciplines. For example, applications of geographic information systems datasets supply a new level of detail to the study of the impacts of sea level rise to coastal zones (Craft et al. 2009). Advances in dynamic and statistical approaches to downscaling have allowed progress in quantifying impacts in diverse arenas such as potential thermal bleaching of coral reefs (Donner et al. 2005) and runoff changes to watersheds (Tsanis et al. 2011). Statistical modeling of crop productivity responses to past climate variations (Schlenker and Roberts 2009) has provided surprising new insights on crop temperature sensitivity and a useful compliment to (rather than a replacement for) longstanding mechanistic (Iglesias et al. 2000; Parry et al. 2004) and hedonic (Mendelsohn et al. 1994) models used for forward projection. In addition to the biophysical information supplied, each of these three methods provides a distinct but limited window on the key question: what is the capacity of humans to adapt to changes in the physical climate and how much of this capacity will be utilized in practice?

Attempts to integrate adaptation responses with analysis of the direct (or static) impacts of climate change are routine for the agricultural sector (Parry et al. 2004) but remain the exception in most impact arenas because our ability to quantify either the adaptive response or its subsequent effects (referred to here as indirect impacts) remain very limited. In the past, the effect of the human response in determining impacts was usually either ignored entirely or noted in a qualitative sense (Cooper et al. 2008). Newer models explicitly incorporate adaptation scenarios in determining impacts, e.g., for sea level rise (Nicholls et al. 2011; Hinkel et al. 2010). The importance of addressing the gap between adaptation capacity and its implementation is recognized (Nicholls and Tol 2006) but largely unaddressed, as is assessment of indirect consequences (to other people and places) of human adaptive responses to the direct impact of physical climate changes. Finally, the role of development in changing the relation between physical impact and outcomes (by increasing or decreasing adaptive capacity) is just now emerging.

In this brief introductory article, I highlight three impact arenas where recent progress illuminates future challenges to assessment and modeling across the broad landscape of human responses. First, I discuss migration of humans and/or economic activity in response to climate change in order to provide insights into the complex question of how primary human responses to climate change may induce ripple effects in the form of large indirect impacts to resources and populations, including some at great distances from the direct impacts. Second, I explore recent insights into the unintended indirect consequences of biofuel production in order to elucidate the complex interaction of emissions mitigation with impacts and adaptation in a warming world. This example provides another perspective on the question of how human responses, in this case anticipatory rather than reactive, can affect humans and natural resources broadly by shifting vulnerability. Third, I use two examples involving direct impacts to human health, recent responses to the risks of heat waves and Indian Ocean cyclones, to emphasize that vulnerability evolves, and as such, future assessments of impacts need to account for varying degrees of learning about climate change and encompass potential responses occurring across diverse development pathways. 
Taken together, these examples illustrate that responses to the direct impacts of climate change lead to important indirect impacts, including some with global reverberations; that adaptation responses interact in important ways with all the other evolving components of development including vulnerability and emissions mitigation policies; and future impacts cannot be reasonably evaluated without insights into how learning from experience with impacts will be incorporated into policies and other responses. A schematic of these interactions is shown in Fig. 1.

\section{Human migration-a response causing indirect impacts}

Attention has been drawn to human migration in response to climate change (Warner et al. 2009) as a result of early claims that these flows could be very substantial, running into the hundreds of millions during the coming decades (Myers and Kent 1995). Migration is a longstanding adaptation to a number of social and environmental stresses (Goldin et al. 2011), including climate variability. The limited number of studies of migration induced by past climate variability and change (for example, McLeman 2009; Saldaña-Zorrilla and

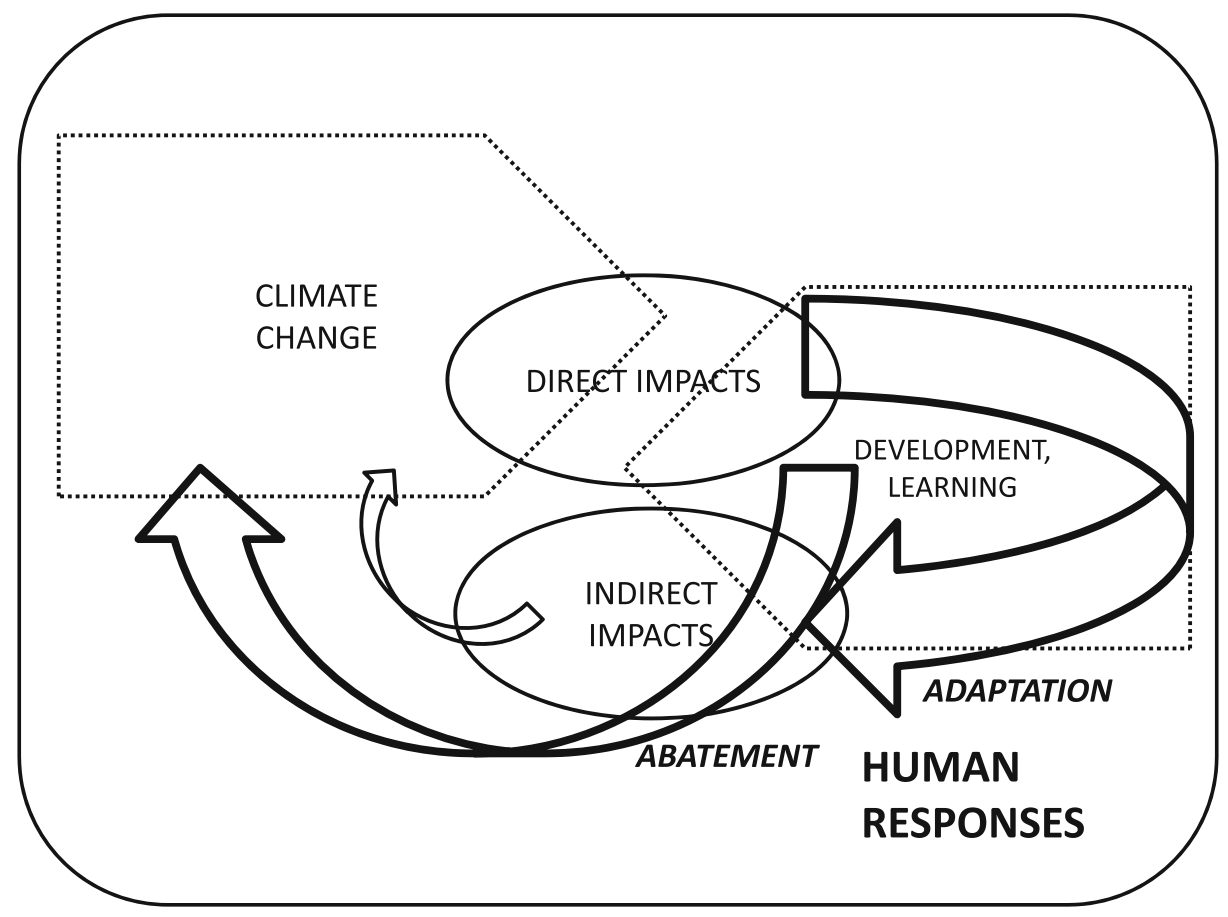

Fig. 1 Human responses to direct impacts of climate change, including adaptation and abatement (emissions mitigation, enhancement of sinks, solar radiation management) are indicated by the thick arrows. Adaptation in response to direct impacts, like changes in migration flows in response to changes in agricultural productivity, lead to indirect impacts at both the source and receiving regions for migrants. Abatement measures, like biofuel cultivation, also lead to indirect impacts like enhanced deforestation and grain price changes, and like the indirect impacts of adaptation, these may influence subsequent climate changes (thin arrow) via their net effects on emissions. The multiple interactions among direct and indirect impacts and development are indicated by the overlapping shapes. Learning about climate change and responses, a component of development, is highlighted as a key feature guiding subsequent responses 
Sandberg 2009) or other, recent environmental stresses (Henry et al. 2003; Massey et al. 2010) indicate 1) a preference for short-range movement within national borders, and 2) a complex relationship to income or wealth, age and gender status with some indication that the poorest are less able to avail themselves of the opportunity to migrate. Pre-existing immigrant networks are critically important to facilitating international migration. Only a few quantitative studies taking into account climate variability and change attempt a modelbased approach to future projection (Barbieri et al. 2010; Feng et al. 2010; Kniveton et al. 2012). On the whole, the recent literature confirms the likelihood of significant increases in climate-driven migration (both internal and external) but with sensitivities to climate which depend on a constellation of other "push" and "pull" factors.

Climate-driven migration is an interesting and complex phenomenon for a number of reasons (Foresight 2011), including that it would transmit an indirect impact of climate change at one location to both ecosystems and species at another. Receiving areas at a range of distances from the initial climate impacts which generate migration would be affected (positively and negatively) by the incoming population. Outcomes would depend on the skills, experiences, cultures, and other personal resources of the migrating and receiving populations and the degree of competition for resources, dislocation, disruption, and even conflict which may arise or be exacerbated. The full range of such outcomes has occurred during past mass migrations (Goldin et al. 2011). Furthermore, the perception of the outcome which materializes in both sending and receiving locations may well vary over time.

Ecosystems would also be subject to the effects of arriving migrants, in some cases resulting in the conversion of unmanaged to cultivated land with implications for biodiversity (Turner et al. 2010). Arguably, these indirect impacts of migration could be as substantial as the direct effects of climate change in the receiving area, but no comparisons of this sort have been developed as yet. For example, episodic and eventually permanent inundation of deltas has the potential to displace hundreds of millions of people during this century (Ericson et al. 2006). Those who move short distances to higher land may remain within national borders while some may attempt to migrate internationally. River deltas in China present a potential example of the former while the Ganges-Meghna-Brahmaputra delta constituting much of Bangladesh presents a potential example of the latter. While the overall migration outcome of past climate variability has been studied where precipitation or temperature change was a factor (Munshi 2003; Feng et al. 2010), I know of no studies exploring past migration responses to sea level change.

Sometimes it would not be the displaced population itself which causes the indirect impact but the displaced economic activity (migrants can take up new occupations and become detached from their former income earning activities). For example, one recent study suggests that a potential relative eastward shift in regions suitable for spring wheat production in South Africa could increase demand for cultivation in regions currently designated for species conservation purposes (Bradley et al. 2012). At the same time, previously-cultivated regions could return to non-agricultural uses, including availability as wildlife habitat (see Fig. 2, derived from Figure 4 in Bradley et al. 2012). While ability to reliably quantify such responses runs up against the limits imposed by the resolution of statistical and dynamic downscaling, the same is true of the direct responses. At present, it is at least possible to identify which areas may be exposed to such changes due to increases or decreases in their relative attractiveness for population influx, cultivation, or other economic activities.

Recent advances based on statistical methods commonly used by micro-economists provide a means to quantify responses to conditions of the recent past and, with appropriate caution, project these under the assumption of a different climate (e.g., Feng et al. 2010 for migration, but also see Auffhammer and Vincent 2012 and Feng and Oppenheimer 2012; Schlenker and Roberts 2009 for agriculture; Burke et al. 2009 for civil conflict). However, 

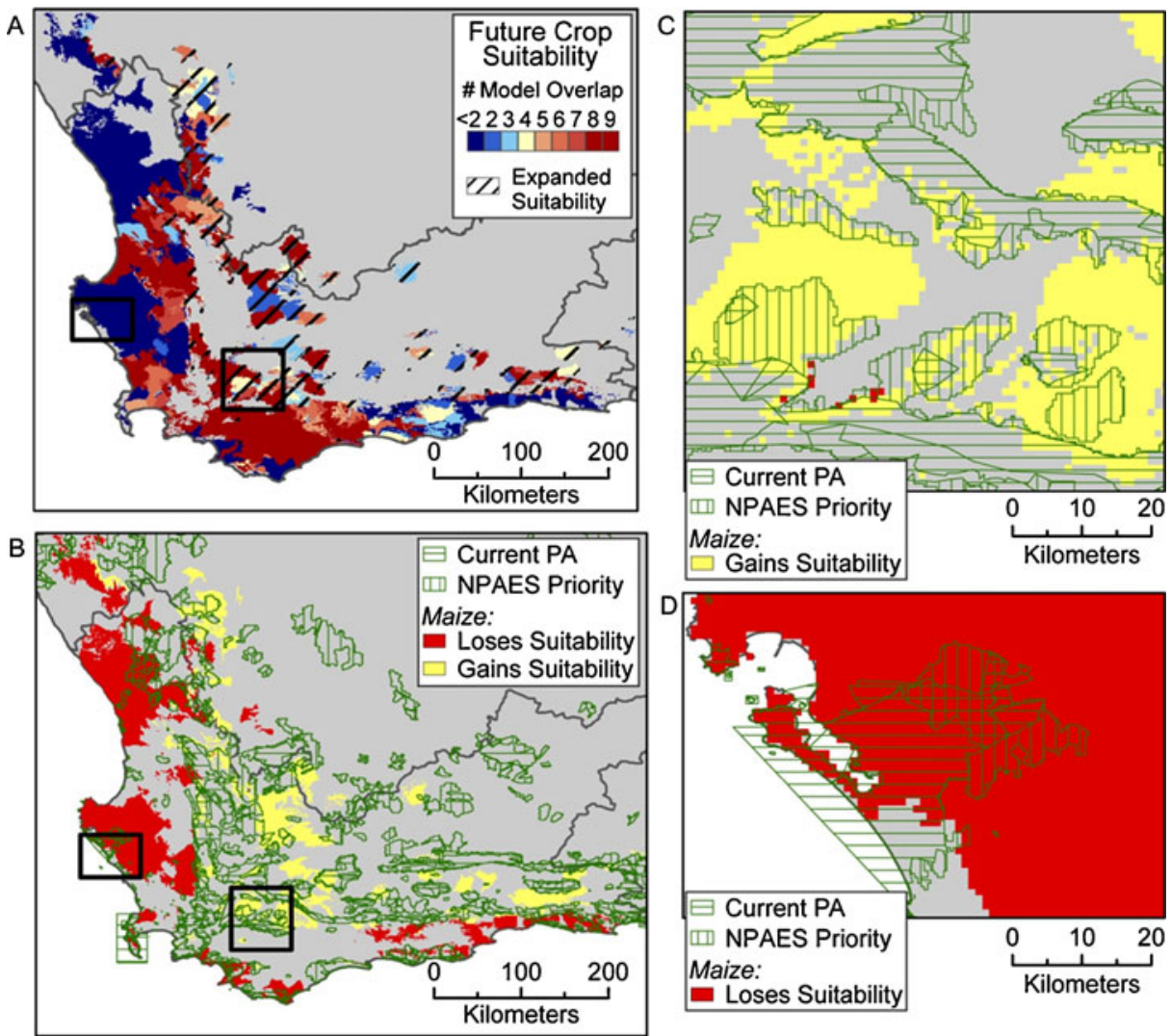

Fig. 2 Changes in climatic suitability for non-irrigated wheat in South Africa based on the B1 emissions scenario (from Bradley et al. 2012, figure 4). a Climate conditions are projected to become less suitable for spring wheat (dark blue areas, indicating $<2$ models projecting future suitability) along the coasts, and increasingly suitable for winter wheat inland at slightly higher elevation (hashed areas). Colors correspond to the number of models in agreement about future suitability. b Areas of overlap between changing wheat suitability $(<2$ models overlapping means loss of current wheat-land $[\mathrm{red}])$; gain is indicated by $2+$ models overlapping in areas currently unsuitable for wheat (yellow) with PAs (currently protected areas) and NPAES (those areas proposed in the National Protected Area Expansion Strategy) indicated by vertical and horizontal green hashes respectively (see Bradley et al. 2012 for details). c Example of increased climatic suitability for wheat surrounding PAs and NPAES expansion priorities. d Example of decreased climatic suitability for wheat surrounding a conservation priority. Panels $\mathbf{c}$ and $\mathbf{d}$ correspond to dark rectangles in panels $\mathbf{a}$ and $\mathbf{b}$

the potential number of reverberations (in Kates 1985 terms, nth-order impacts) of a direct climate impact is large, including, for example via the interlinked global market system (Wise et al. 2009; also see sections 3 and 5 below), so such projections are merely a first step at revealing the full range of potential outcomes of climate change.

\section{Crops for biofuel production-how mitigation complicates the assessment of impacts}

It has long been known that adaptation actions bear consequences for mitigation strategies, e.g., projected increases in cooling and decreases in heating requirements bear modest implications for global strategies to mitigate carbon dioxide emissions. A new focus is 
developing on the impacts which accompany greenhouse gas mitigation responses and the consequences of these impacts for adaptation to the broader range of impacts of climate change. Many analyses have explored the potential for expanded exploitation of biofuels as an alternative to fossil fuels in transportation, electricity generation, and domestic energy use (see NAS 2009a, b). Full exploitation of this technology would require substantial land use change, including a redirection of agriculture from food production, silvaculture from timber production, and unmanaged land or land managed for conservation purposes (Turner et al. 2010 ) to cultivation of crops for biofuel production (energy crops). While the broad tradeoffs were identified long ago, quantitative assessment is relatively recent (Fargione et al. 2008; Searchinger et al. 2008) including: the indirect economic effects on food prices as food and energy production compete for land (Wise et al. 2009); the indirect response of converting unmanaged land (or land managed for conservation) to produce energy crops as demand for food-crop cultivation is displaced geographically (Searchinger et al. 2008); and increased demand for water used in fuel production. Strategies have been proposed to ameliorate these impacts including via increased efficiency of crop residue and land use and crop-to-energy conversion (NAS 2009b).

These indirect impacts of mitigation will interact with adaptation responses to the shifting climate context in which the land-food-water interaction will occur in the future. On a local scale, for example, the suitability for cultivation of certain food crops is expected to decrease in some areas while increasing in others, eventually having net negative effects on production in low-latitude, developing countries (Easterling et al. 2007). Simultaneous competition for land between food and energy crops elsewhere would reduce the buffering effect provided by the global market for agricultural commodities, imposing a significant obstacle to successful adaptation to even gradual climate change. Recent food price increases reflect the effects of such demand for energy crops, along with the influence of climate change and higher energy costs to farmers among other factors (Wright 2011; Lobell et al. 2011).

Taking a broader view, this example suggests that modeling impacts in such a complex system may not produce meaningful projections unless carried out in the context of integrated assessment of adaptation and mitigation responses. Developing models to assess the regional outcomes of such tradeoffs (Wise et al. 2009) is extremely challenging, despite recent initial steps, partly because the related land use decisions occur in a local and disaggregated manner which is difficult to analyze. On the other hand, the resulting aggregate consequences ripple through the global markets and are more tractable to modeling (see section 5).

Another difficulty arises from the nature of both mitigation and adaptation planning and implementation: the former is often controlled at the national level with a limited number of emitter nations determining global outcomes for fuel use and emissions, with (currently) modest amounts of international governance for coordination purposes, and detailed implementation at the subnational level. On the other hand, while adaptation planning and implementation involve all scales of governance, these activities tend to be biased toward smaller scales yet involve communities in all countries. These disjunctions increase the chances that, in the current example, decisions on fuel policy would be decoupled from their consequences, and from the burden of adapting to the consequences (a well-known conundrum characterizing the entire climate problem). Such disjunctions complicate the development of policy scenarios from which to assess impacts.

Biofuels do not stand alone among the climate change mitigation responses which could significantly complicate adaptation. Solar radiation management (a form of geoengineering) could offset global mean warming but would not bring the planet back to the same climate state historically associated with a given mean temperature. Rather, a distinct, new set of regional climates would appear, leading to their own adaptation challenges. Once again, the 
governance disjunction noted above would complicate analysis of responses and their indirect impacts (Lloyd and Oppenheimer 2011).

\section{Accounting for the evolution of vulnerability}

While climate impact analysis in some sectors, notably agriculture (Parry et al. 2004), has attempted to integrate human responses by accounting in part for the potential to adapt, such approaches are generally unable to estimate the full interaction among individuals, socioeconomic systems, and the climate. Ideally, direct and indirect impacts would be assessed in the context of development scenarios which capture vulnerability as an evolving feature rather than a static set of capacities and limits. Such scenarios would also capture the evolving and cumulative mitigation response to climate change (see section 3).

The SRES (Nakicenovic and Swart 2000) represented a potential step in this direction. However, they were mainly used in impact analysis to determine a range of climate futures rather than the range of human responses, since these scenarios explicitly ignored the ongoing response to climate change in either adaptation or mitigation. Emerging approaches for integrating climate change, climate policy, and development into new socioeconomic pathways (Kriegler et al. 2010; Hallegatte et al. 2011) may provide an improved basis for analysis of vulnerability and impacts.

Responses would also be dynamic due to individual and societal learning resulting in changes in individual perception of risk as well as "objective" risk (Grothmann and Patt 2005; Lambin 2005). Deaths in heat waves in developed countries may be viewed as examples of failed adaptation, or adaptation in practice falling short of theoretical adaptation capacity. However, the devastating western European heat wave of 2003 was followed by another severe heat wave in France in 2006 when anticipatory responses (such as early warning systems) were apparently much improved and mortality two-thirds lower according to one study, suggesting rapid learning (Fouillet et al. 2008). Responses to Indian Ocean cyclones provide a more complex case reflecting the effects of both development in general and learning related to extreme events in particular. A combination of early warning systems, wetland enhancements, provision of shelter, and increased forecasting capacity implemented in response to earlier disastrous cyclone impacts appears to have led to mortality rates in Bangladesh which are lower by more than an order of magnitude compared to both historical experience and experience in neighboring Myanmar (IPCC 2012).

How much staying power such knowledge has with respect to widely-spaced extreme events remains uncertain and how to capture such learning in scenarios which determine the evolution of vulnerability is an untouched area of climate impact modeling. With sufficient information under conditions of gradual climate change and well-functioning markets and other institutions (see Nordhaus 2010 on adaptation to hurricanes in the US), adaptation may be represented as a straightforward and implicit component of development. But particularly if climate changes rapidly and risk estimation is difficult, or, as in many developing countries, lack of information and unequal distribution of resources impede responses, explicit learning from extreme events like the ones above may be crucial.

\section{Prospects}

While limits on our knowledge and modeling capabilities have resulted in much current impact analysis treating humans and societies as passive recipients of the impacts of climate 
change, it has long been recognized that the result is a flattened representation. Instead, humans will respond to both the realization and the anticipation of climate change in ways which will in some cases ameliorate hypothetical impacts, aggravate these impacts in other cases, and displace the impacts or cause different impacts in yet others. In some instances, anticipated climate impacts may be effectively offset (although, rarely at no cost). In others, at least on a regional and local basis, the indirect impacts caused by some responses may be of the same or even greater magnitude (although not necessarily to the same people or places) as the direct impacts which triggered them. These responses result in a complex amalgam of direct and indirect impacts, local and distant impacts, immediate and delayed impacts. Furthermore, socioeconomic conditions embodied in potential development pathways as well as a wide range of other factors will shape such responses, and heavily influence the overall outcomes (Adger 2006).

At this juncture, the mere outlines of approaches for taking all these factors into account are beginning to emerge. Some encouraging methodological advances are occurring which provide at least a partial way forward, particularly if different methods can be combined to provide a holistic approach to evaluation of impacts. Among these is the application of economic models to reveal the global ripple effects of policy responses as they influence supply, demand, and trade in marketable goods, as demonstrated in analysis of the biofuel problem discussed in section 3 (Wise et al. 2009). Responses like these, including indirect impact pathways such as the trade in "virtual water" have been modeled for the coupled water-agriculture system (Calzadilla et al. 2011) although in the latter case, the specific effect of climate change, as well as policy responses to climate change, remain to be incorporated. Such modeling can provide important insights where value can be monetized and indirect effects propagate globally and regionally via markets, and eventually should be extended by implementation of probabilistic and multi-metric frameworks for evaluating risk (Schneider et al. 2007).

But indirect and distant effects involving goods and services which aren't readily priced or quantified are a much greater challenge to modeling. The migration response, discussed in section 2, provides a rich example. Changes in labor markets as a result of the direct impacts of climate change (such as increased or reduced crop productivity), may be amenable to modeling but are only one of several pushes and pulls, evaluated through multiple perceptions of risk and uncertainty, which affect individual adaptation decisions. We are only beginning to grapple with the daunting range of direct and indirect interactions and scales involved and the diverse tools needed to produce a coherent picture and perhaps some predictive skill (Piguet 2010; Kniveton et al. 2012).

For example, exploitation of statistical methods (Feng et al. 2010; Schlenker and Roberts 2009) facilitates inference of the sensitivity of various human responses to past climate variations and changes, and enables the use of the latter in forward projection where processbased models are either too limited in skill or nonexistent. A critical next step is to contextualize such top-down, quantitative studies by combining them with differentiated, community-based, studies (Liverman 1990) comprehensively across the impacts arena in order to gain an understanding of the diverse human motivations which will drive these responses.

In the end, the key question remains: what is the purpose of impact assessment? If the aim is to produce quantitative projections of climate impacts under a range of plausible development scenarios, then given this complexity, we are a very long way from achieving our goal. But a more modest objective is within reach: to achieve a qualitative understanding of what combination of climate changes and other factors, occurring locally and at a distance, may expose particular regions and communities to impacts to which they are vulnerable, in order to better inform decision makers at all levels of governance. 
Open Access This article is distributed under the terms of the Creative Commons Attribution License which permits any use, distribution, and reproduction in any medium, provided the original author(s) and the source are credited.

\section{References}

Adger WN (2006) Vulnerability. Glob Environ Chang 16:268-281

Auffhammer M, Vincent JR (2012) Unobserved time effects confound the identification of climate change impacts. Proc Natl Acad Sci. www.pnas.org/cgi/doi/10.1073/pnas.1202049109

Barbieri AF, Domingues E, Queiroz BL, Ruiz RM, Rigotti JI, Carvalho JAM, Resende MF (2010) Climate change and population migration in Brazil's Northeast: scenarios for 2025-2050. Popul Environ 31:344370. doi:10.1007/s11111-010-0105-1

Bradley BA, Estes LD, Hole DG, Holness S, Oppenheimer M, Turner WR, Wilcove DS (2012) Predicting how adaptation to climate change could affect ecological conservation: secondary impacts of shifting agricultural suitability. Divers Distrib18:425-437. http://onlinelibrary.wiley.com/doi/10.1111/j.14724642.2011.00875.x/pdf

Burke MB, Miguel E, Satyanath S, Dykema JA, Lobell DB (2009) Warming increases the risk of civil war in Africa. PNAS 106:20670-20674

Calzadilla A, Rehdanz K, Tol RSJ (2011) Water scarcity and the impact of improved irrigation management: a computable general equilibrium analysis. Agric Econ 42:305-323. doi:10.1111/j.1574-0862.2010.00516.x

Cooper MP, Beevers MD, Oppenheimer M (2008) The potential impacts of sea level rise on the coastal region of New Jersey, USA. Clim Chang 90:475-492. doi:10.1007/s10584-008-9422-0

Craft C, Clough J, Ehman J, Joye S, Park R, Pennings S, Guo H, Machmuller M (2009) Forecasting the effects of accelerated sea-level rise on tidal marsh ecosystem services. Front Ecol Environ 7(2):73-78. doi:10.1890/070219

Donner SD, Little CM, Oppenheimer M, Hoegh-Guldberg O (2005) Global assessment of coral bleaching and required rates of adaptation under climate change. Glob Chang Biol 11(12):2251-2265

Easterling WE, Aggarwal PK, Batima P, Brander KM, Erda L, Howden SM, Kirilenko A, Morton J, Soussana J-F, Schmidhuberand J, Tubiello FN (2007) Food, fibre and forest products. In: Parry ML, Canziani OF, Palutikof JP, van der Linden PJ, Hanson CE (eds) Climate change 2007: impacts, adaptation and vulnerability. Contribution of working group II to the fourth assessment report of the intergovernmental panel on climate change. Cambridge University Press, Cambridge, pp 273-313

Ericson JP, Vörösmarty CJ, Dingman SL, Ward LG, Meybeck M (2006) Effective sea-level rise and deltas: causes of change and human dimension implications. Glob Planet Chang 50:63-82

Fargione J, Hill J, Tilman D, Polasky S, Hawthorne P (2008) Land clearing and the biofuel carbon debt. Science 319:1235-1238

Feng S, Krueger A, Oppenheimer M (2010) Linkages among climate change, crop yields and Mexico-US cross-border migration. Proc Natl Acad Sci 107(32):14257-14262. www.pnas.org/cgi/doi/10.1073/ pnas. 1002632107

Feng S, Oppenheimer M (2012) Applying statistical models to the climate-migration relationship. Proc Natl Acad Sci. www.pnas.org/cgi/doi/10.1073/pnas.1212226109

Foresight (2011) Foresight: migration and global environmental change final project report. The Government Office for Science, London

Fouillet A, Rey G, Wagner V, Laaidi K, Empereur-Bissonnet P, Le Tertre A, Frayssinet P, Bessemoulin P, Laurent F, De Crouy-Chanel P, Jougla E, He'mon D (2008) Has the impact of heat waves on mortality changed in France since the European heat wave of summer 2003? A study of the 2006 heat wave. Int J Epidemiol 37:309-317. doi:10.1093/ije/dym253

Goldin I, Cameron G, Balarajan M (2011) Exceptional people: how migration shaped our world and will define our future. Princeton University Press, Princeton

Grothmann T, Patt A (2005) Adaptive capacity and human cognition: the process of individual adaptation to climate change. Glob Environ Chang 15(3):199-213

Hallegatte S, Przyluski V, Vogt-Schilb A (2011) Building world narratives for climate change impact, adaptation and vulnerability analyses. Nat Clim Chang 1:151-155. doi:10.1038/NCLIMATE1135

Henry S, Boyle P, Lambin EF (2003) Modelling inter-provincial migration in Burkina Faso, West Africa: the role of sociodemographic and environmental factors. Appl Geogr 23:115-136

Hinkel J, Nicholls RJ, Vafeidis AT, Tol RSJ, Avagianou T (2010) Assessing risk of and adaptation to sea-level rise in the European Union: an application of DIVA. Mitig Adapt Strateg Glob Chang 15:703-719. doi:10.1007/s11027-010-9237-y 
Iglesias A, Rosenzweig C, Pereira D (2000) Prediction spatial impacts of climate in agriculture in Spain. Glob Environ Chang 10:69-80

IPCC (2012) Managing the risks of extreme events and disasters to advance climate change adaptation, Special Report of the Intergovernmental Panel On Climate Change, Cambridge University Press, Cambridge and New York, Chapter 9

Kates RW (1985) The interaction of climate and society. In: Kates RW, Ausubel JH, Berberian M (eds) Climate impact assessments: studies of the interaction of climate and society. Wiley, New York, pp 3-36

Kniveton DR, Smith CD, Black R (2012) Emerging migration flows in a changing climate in dryland Africa. Nature Clim Change. doi:10.1038/NCLIMATE1447

Kriegler E et al (2010) Socioeconomic scenario development for climate change analysis at http://www.ipccwg3.de/meetings/expert-meetings-and-workshops/files/Kriegler-et-al-2010-Scenarios-for-ClimateChange-Analysis-Working-Paper-2010-10-18.pdf

Lambin EF (2005) Conditions for sustainability of human-environment systems: information, motivation, and capacity. Glob Environ Chang 15(3):177-180

Liverman DM (1990) Drought impacts in Mexico: climate, agriculture, technology, and land tenure in Sonora and Puebla. Ann Assoc Am Geogr 80:49-72

Lloyd ID, Oppenheimer M (2011) On the design of an international governance framework for geoengineering. Submitted to Global Environmental Politics

Lobell DB, Schlenker W, Costa-Roberts J (2011) Climate trends and global crop production since 1980. Science www.sciencexpress.org/5May2011/Page1/10.1126/science.1204531

Massey DS, Axinn WG, Ghimire DJ (2010) Environmental change and out-migration: evidence from Nepal. Popul Environ 32(2-3):109-113

McLeman R (2009) Climate change and adaptive human migration: lessons from rural North America. In: Adger NW, Lorenzoni I, O'Brien KL (eds) Adapting to climate change: thresholds, values, governance. Cambridge University Press, Cambridge

Mendelsohn R, Nordhaus WD, Shaw D (1994) The impact of global warming on agriculture: a Ricardian analysis. Am Econ Rev 84(4):753-771

Munshi K (2003) Networks in the modern economy: Mexican migrants in the U.S. labor market. Q J Econ 118:549-599

Myers N, Kent J (1995) Environmental exodus: an emergent crisis in the global arena climate institute. Washington, DC

Nakicenovic N, Swart R (eds) (2000) Emissions scenarios, IPCC special report. Cambridge University Press, UK

NAS (2009a) America's energy future: technology and transformation: summary edition committee on America's energy future; National Academy of Sciences; National Academy of Engineering; National Research Council. National Academy Press, Washington, DC

NAS (2009b) Liquid transportation fuels from coal and biomass: technological status, costs, and environmental impacts. America's Energy Future Panel on Alternative Liquid Transportation Fuels, National Academy of Sciences; National Academy of Engineering; National Research Council. National Academy Press, Washington, DC

Nicholls RJ, Marinova N, Lowe JA, Brown S, Vellinga P, De Gusmão D, Hinkels J, Tol RSJ (2011) Sea-level rise and its possible impacts given a 'beyond $4^{\circ} \mathrm{C}$ world' in the twenty-first century. Phil Trans R Soc A 369:161-181. doi:10.1098/rsta.2010.0291

Nicholls RJ, Tol RSJ (2006) Impacts and responses to sea-level rise: a global analysis of the SRES scenarios over the twenty-first century. Phil Trans R Soc A 364:1073-1095. doi:10.1098/rsta.2006.1754

Nordhaus WD (2010) The economics of hurricanes and implications of global warming. Clim Chang Econ 1 (1): $1-20$

Parry ML, Rosenzweig C, Iglesias A, Livermore M, Fischer G (2004) Effects of climate change on global food production under SRES emissions and socio-economic scenarios. Glob Environ Chang 14(1):53-67. doi:10.1016/j.gloenvcha.2003.10.008

Piguet E (2010) Linking climate change, environmental degradation, and migration: a methodological overview. WIREs Clim Chang 1:517-524

Saldaña-Zorrilla S, Sandberg K (2009) Impact of climate-related disasters on human migration in Mexico: a spatial model. Clim Chang 96:97-118

Schlenker W, Roberts M (2009) Nonlinear temperature effects indicate severe damages to U.S. crop yields under climate change. PNAS 106:15594-15598

Schneider SH, Semenov S, Patwardhan A, Burton I, Magadza CHD, Oppenheimer M, Pittock AB, Rahman A, Smith JB, Suarez A, Yamin F (2007) Assessing key vulnerabilities and the risk from climate change. In: Parry ML, Canziani OF, Palutikof JP, van der Linden PJ, Hanson CE (eds) Climate change 2007: impacts, adaptation and vulnerability. Contribution of working group II to the fourth 
assessment report of the intergovernmental panel on climate change. Cambridge University Press, Cambridge, pp 779-810

Searchinger T, Heimlich R, Houghton RA, Dong F, Elobeid A, Fabiosa J, Tokgoz S, Hayes D, Yu T-H (2008) Use of US croplands for biofuels increases greenhouse gas emissions through land use change. Science 319:1238-1240

Tsanis IK, Koutroulis AG, Daliakopoulos IN, Jacob D (2011) Severe climate-induced water shortage and extremes in Crete. Clim Chang 106:667-677. doi:10.1007/s10584-011-0048-2

Turner WR, Bradley BA, Estes LD, Hole DG, Oppenheimer M, Wilcove DS (2010) Climate change: helping nature survive the human response. Conserv Lett 3(5):304-312. doi:10.1111/j.1755263X.2010.00128.x

Warner K et al (2009) In search of shelter: mapping the effects of climate change on human migration and displacement (United Nations University, CARE, and CIESIN, Columbia University and in close collaboration with the European Commission "Environmental Change and Forced Migration Scenarios Project", the UNHCR, and the World Bank, Bonn, Germany)

Williams J (ed) (1978) Proceedings of an IIASA workshop on carbon dioxide, climate, and society. Pergamon, Oxford

Wise M, Calvin K, Thomson A, Clarke L, Bond-Lamberty B, Sands R, Smith SJ, Janetos A, Edmonds J (2009) Implications of limiting CO2 concentrations for land use and energy. Science 324:1183

Wright BD (2011) The economics of grain price volatility. Appl Econ Perspect Policy 33(1):32-58. doi:10.1093/aepp/ppq033 